\title{
Effect of amiodarone on retrograde conduction and refractoriness of the His-Purkinje system in man
}

\author{
C P REDDY, C S KUO \\ From the Cardiology Division, Department of Medicine, Veterans Administration Medical Center and University of \\ Kentucky College of Medicine, Lexington, Kentucky, USA
}

SUMMARY The effects of long term treatment with oral amiodarone on retrograde conduction $\left(\mathrm{S}_{2} \mathrm{H}_{2}\right.$ interval) and refractoriness of the His-Purkinje system were studied in 11 patients using His bundle electrograms and the ventricular extrastimulus method. Ten patients had ventricular tachycardia and one supraventricular tachycardia. Electrophysiological studies were carried out before and after the patients had been taking their maintenance dose for a mean duration of 84 days. After amiodarone treatment the $\mathrm{HV}$ interval was prolonged in seven patients and unchanged in four. At comparable $\mathrm{S}_{1} \mathrm{~S}_{2}$ intervals, the $\mathrm{S}_{2} \mathrm{H}_{2}$ intervals were longer after treatment with amiodarone in all patients than before. Similarly, the longest $\mathrm{S}_{2} \mathrm{H}_{2}$ intervals achieved after amiodarone were longer than the control values. Amiodarone significantly increased the relative, effective, and functional refractory periods of the His-Purkinje system. Thus amiodarone exerts important effects on the His-Purkinje system.

Amiodarone was originally introduced as a coronary vasodilator and antianginal agent in 1967.' Subsequent studies have shown that amiodarone has pronounced antiarrhythmic properties with beneficial effect in a wide variety of arrhythmias..$^{2-4}$ The electrophysiological actions responsible for the antiarrhythmic effect of amiodarone are, however, poorly understood. Several clinical studies have evaluated the effects of amiodarone on the functional properties of the atrioventricular node,, 56 atrioventricular accessory pathways, ${ }^{7}$ and ventricular myocardium.$^{8-10}$ Nevertheless, the effects of amiodarone on conduction and refractoriness of the His-Purkinje system have not been systematically studied, and there is no agreement on the effects of amiodarone on the system. Whereas Heger et $\mathrm{l}^{9}$ and others ${ }^{8} 11$ reported prolongation of the HV interval by amiodarone, Nademanee et al found no effect on this interval. ${ }^{10}$ Similarly, conflicting results have been reported concerning the effect of amiodarone on the refractoriness of the HisPurkinje system. ${ }^{512}$ The present study was undertaken to assess the effect of long term treatment with oral amiodarone on retrograde conduction and refrac-

Reprint requests to Dr C Pratap Reddy, Cardiology Division, 111B Medical Service, Veterans Administration Medical Center, Lexington, KY 40511, USA.

Accepted for publication 31 January 1984 toriness of the His-Purkinje system in a group of patients in order to increase our understanding of the mechanism of the antiarrhythmic effects of amiodarone.

\section{Patients and methods}

The study group consisted of 11 men aged between 38 and 73 (mean 59.8) years. Ten patients had recurrent ventricular tachycardia or ventricular fibrillation and one supraventricular tachycardia refractory to treatment with two or more approved antiarrhythmic drugs. Coronary artery disease was present in nine patients and no evidence of organic heart disease in two. All patients with coronary artery disease had suffered one or more myocardial infarctions.

Amiodarone was given as a loading dose of $1400 \mathrm{mg}$ (four patients) or $1000 \mathrm{mg}$ (seven patients) daily for an initial loading period ranging from 7 to 14 (mean $( \pm S D) \quad 10 \cdot 2 \pm 2 \cdot 2)$ days. Subsequently, all patients were given a maintenance dose of 400 to $800 \mathrm{mg}$ daily.

Electrophysiological studies were performed in each patient before and after the patients had been taking their maintenance dose for 23 to 149 (mean ( \pm SD) $84 \pm 45$ ) days. Repeat studies were carried out to assess the efficacy of amiodarone in suppressing ventricular tachycardia. The mean total accumulated dose of amiodarone at the time of repeat study was 
$63.5 \pm 32.6 \mathrm{~g}$ (range $18 \cdot 4-106.8 \mathrm{~g}$ ). These studies were performed using the standard pacing wire technique ${ }^{13}$ after informed consent had been obtained. Programmed stimulation was performed using a digital stimulator which delivered pulses of $1 \mathrm{~ms}$ duration at twice the diastolic threshold.

The study protocol consisted of (a) incremental ventricular pacing to study the ventriculoatrial conduction; $(b)$ retrograde refractory period studies at one or more basic cycle lengths, and $(c)$ induction of ventricular tachycardia using single and double ventricular extrastimuli introduced during ventricular pacing.

Statistical analysis of electrophysiological data was performed using Student's $t$ test for paired and unpaired data.

\section{DEFINITION OF TERMS}

$\mathrm{S}_{1}, \mathrm{~V}_{1}, \mathrm{H}_{1}, \mathrm{~A}_{1}$ represent the stimulus artefact, ventricular electrogram, His bundle electrogram, and atrial electrogram of the basic drive complex respectively. $\mathrm{S}_{2}, \mathrm{~V}_{2}, \mathrm{H}_{2}, \mathrm{~A}_{2}$ represent the stimulus artefact, ventricular electrogram, His bundle electrogram, and atrial electrogram of the induced extrasystole respectively. The SH interval was measured from the stimulus artefact to the onset of the His bundle electrogram. ${ }^{14}$

Anterograde conduction intervals were defined as previously reported. ${ }^{15}$

Relative refractory period of the His-Purkinje system is the longest $V_{1} V_{2}$ interval at which $\mathrm{H}_{2}$ emerges from the $V_{2}$ electrogram. This definition was used with the knowledge that the true relative refractory period exceeds the defined value by a small amount since infra-His bundle delay must occur before $\mathrm{H}_{2}$ can emerge from the $V_{2}$ electrogram.
Functional refractory period of the His-Purkinje system is the shortest $\mathrm{V}_{1} \mathrm{H}_{2}$ interval in response to any $\mathrm{V}_{1}$ $\mathrm{V}_{2}$ interval. This definition was used with the knowledge that prolongation of the $\mathrm{V}_{1} \mathrm{H}_{1}$ interval by amiodarone diminishes any actual increase in the functional refractory period.

Effective refractory period of the His-Purkinje system was defined as previously described. ${ }^{16}$

Effective refractory period and functional refractory period of the ventricular myocardium were defined as previously reported. ${ }^{16}$

$\mathrm{S}_{2} \mathrm{H}_{2}$ block zone ${ }^{17}$ refers to the range of $\mathrm{S}_{1} \mathrm{~S}_{2}$ intervals during which the $S_{2}$ impulse is blocked retrogradely in both bundle branches distal to the site of stimulation but proximal to the His bundle recording site.

\section{Results}

The Table shows the retrograde electrophysiological data for individual patients and for the group as a whole. In control studies seven of 11 patients had 1:1 ventriculoatrial conduction during basic drive. After amiodarone ventriculoatrial conduction was present in one patient and absent at all ventricular drive rates in 10 .

RETROGRADE HIS-PURKINJE CONDUCTION TIME At long $\mathrm{S}_{1} \mathrm{~S}_{2}$ intervals the His bundle electrogram $\left(\mathrm{H}_{2}\right)$ of the extrasystoles $\left(\mathrm{V}_{2}\right)$ was hidden within the $\mathrm{V}_{2}$ electrogram, but at shorter $S_{1} S_{2}$ intervals retrograde conduction to the His bundle became slower, and the $\mathrm{H}_{2}$ deflection emerged from the ventricular electrogram $\left(\mathrm{V}_{2}\right)$ (Fig. 1). Once the retrograde His bundle deflection $\left(\mathrm{H}_{2}\right)$ emerged from the $\mathrm{V}_{2}$ electrogram further decrease in $S_{1} S_{2}$ interval resulted in a

ble Retrograde refractory periods during control $(C)$ study and after treatment with amiodarone (A)

\begin{tabular}{|c|c|c|c|c|c|c|c|c|c|c|c|c|c|c|c|}
\hline \multirow[t]{3}{*}{ se } & \multirow[t]{3}{*}{$C L$} & \multirow{2}{*}{\multicolumn{2}{|c|}{$\underset{\text { interval (ms) }}{\text { Longest }}{\underset{\text { I }}{\mathrm{m}_{2}} \mathrm{H}_{2}}$}} & \multicolumn{6}{|c|}{ Refractory periods of His-Purkinje system (ms) } & \multicolumn{4}{|c|}{ Refractory periods of ventricular muscle (ms) } & \multirow{2}{*}{\multicolumn{2}{|c|}{$\begin{array}{l}\text { HV interval of sinus } \\
\text { rhythm (ms) }\end{array}$}} \\
\hline & & & & \multicolumn{2}{|c|}{ Relative } & \multicolumn{2}{|c|}{ Effective } & \multicolumn{2}{|c|}{ Functional } & \multicolumn{2}{|c|}{ Effective } & \multicolumn{2}{|c|}{ Functional } & & \\
\hline & & $C$ & $A$ & $C$ & $\boldsymbol{A}$ & $C$ & $\boldsymbol{A}$ & $C$ & $\boldsymbol{A}$ & $C$ & $A$ & $C$ & $\boldsymbol{A}$ & $C$ & $A$ \\
\hline & $\begin{array}{l}670 \\
800 \\
600 \\
600 \\
600 \\
500 \\
700 \\
700 \\
600 \\
500 \\
550 \\
\\
\end{array}$ & $\begin{array}{r}220 \\
260 \\
205 \\
200 \\
195 \\
200 \\
230 \\
250 \\
220 \\
150 \\
165 \\
208 \cdot 6 \\
\pm 32 \cdot 8 \\
<0\end{array}$ & $\begin{array}{l}250 \\
305 \\
250 \\
200 \\
260 \\
245 \\
270 \\
295 \\
320 \\
170 \\
200 \\
260 \cdot 4 \\
\pm 38 \cdot 3 \\
1\end{array}$ & $\begin{array}{c}340 \\
380 \\
330 \\
300 \\
290 \\
290 \\
320 \\
320 \\
330 \\
290 \\
300 \\
317 \cdot 3 \\
\pm 27 \cdot 6 \\
<0 .\end{array}$ & $\begin{array}{l}360 \\
400 \\
360 \\
320 \\
330 \\
310 \\
340 \\
330 \\
360 \\
320 \\
340 \\
342 \cdot 7 \\
\pm 25 \cdot 7 \\
01\end{array}$ & $\begin{array}{l}300 \\
310 \\
270 \\
300 \\
<240 \\
<230 \\
300 \\
290 \\
<275 \\
<270 \\
<275 \\
295 \\
\pm 13.7 \\
\quad<0.0\end{array}$ & $\begin{array}{l}370 \\
350 \\
320 \\
340 \\
290 \\
<265 \\
350 \\
300 \\
335 \\
320 \\
350 \\
338 \\
\pm 24.8 \\
5\end{array}$ & $\begin{array}{r}480 \\
540 \\
445 \\
455 \\
440 \\
405 \\
505 \\
515 \\
480 \\
405 \\
435 \\
464 \\
\pm 44 \\
<\end{array}$ & $\begin{array}{l}550 \\
600 \\
505 \\
510 \\
510 \\
480 \\
580 \\
550 \\
645 \\
465 \\
505 \\
536 \cdot 3 \\
\pm 54.5 \\
01\end{array}$ & $\begin{array}{l}270 \\
260 \\
220 \\
250 \\
220 \\
210 \\
270 \\
230 \\
270 \\
260 \\
260 \\
247 \cdot 2 \\
\pm 22 \cdot 8 \\
<0\end{array}$ & $\begin{array}{l}310 \\
290 \\
240 \\
270 \\
250 \\
240 \\
290 \\
250 \\
320 \\
300 \\
310 \\
280 \\
\pm 30 \\
1\end{array}$ & $\begin{array}{l}280 \\
285 \\
240 \\
260 \\
240 \\
230 \\
285 \\
240 \\
275 \\
270 \\
280 \\
262 \cdot 3 \\
\pm 21 \\
<\end{array}$ & $\begin{array}{l}320 \\
310 \\
265 \\
310 \\
275 \\
265 \\
310 \\
260 \\
335 \\
315 \\
335 \\
300 \\
\pm 28.3 \\
1\end{array}$ & $\begin{array}{l}30 \\
50 \\
55 \\
50 \\
45 \\
50 \\
45 \\
45 \\
55 \\
40 \\
45 \\
46 \cdot 3 \\
\pm 7 \cdot 1 \\
<\end{array}$ & $\begin{array}{l}45 \\
50 \\
55 \\
55 \\
55 \\
55 \\
50 \\
45 \\
75 \\
40 \\
65 \\
53.6 \\
\pm 9.8 \\
25\end{array}$ \\
\hline
\end{tabular}

, cycle length. 


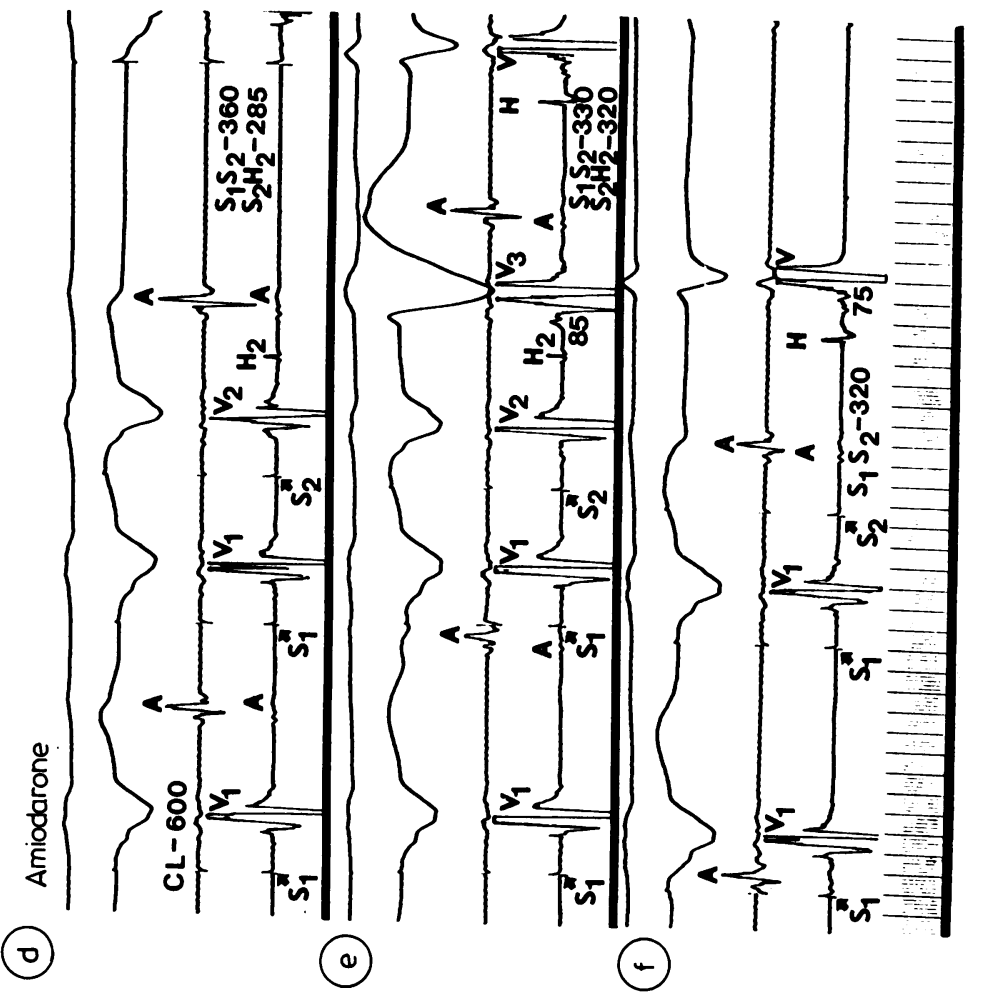

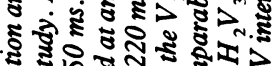

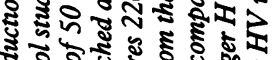

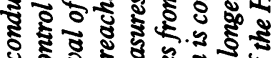

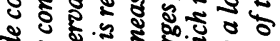

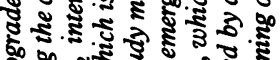

ใั้ ฐ

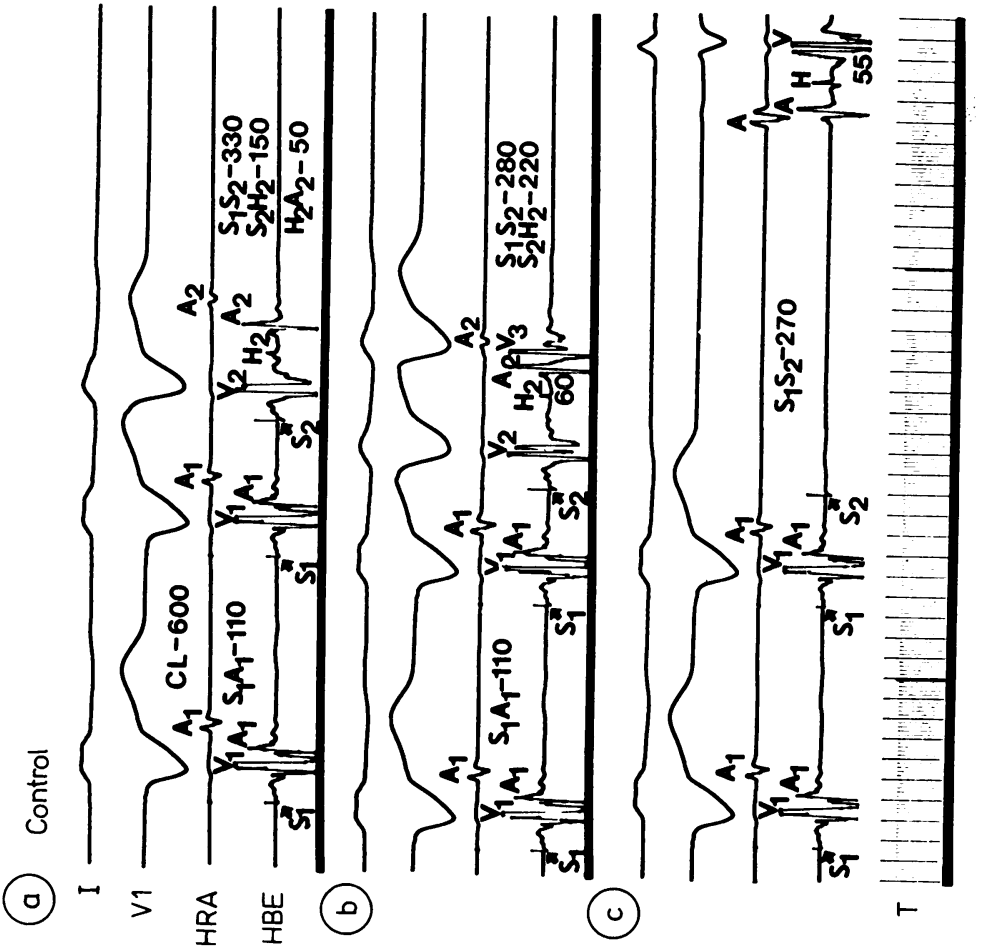

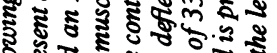

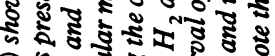

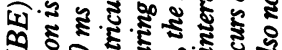

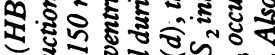

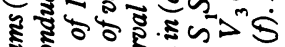

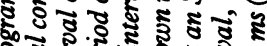

놀

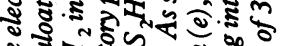

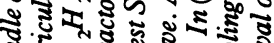

हैं कू

:

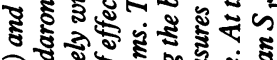

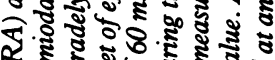

रूล

ชิ

है ₹

ธิ

过要资

ㄱำ

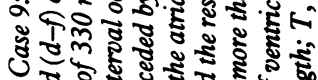

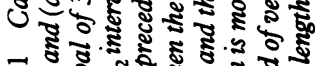

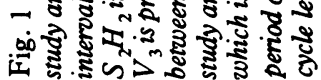




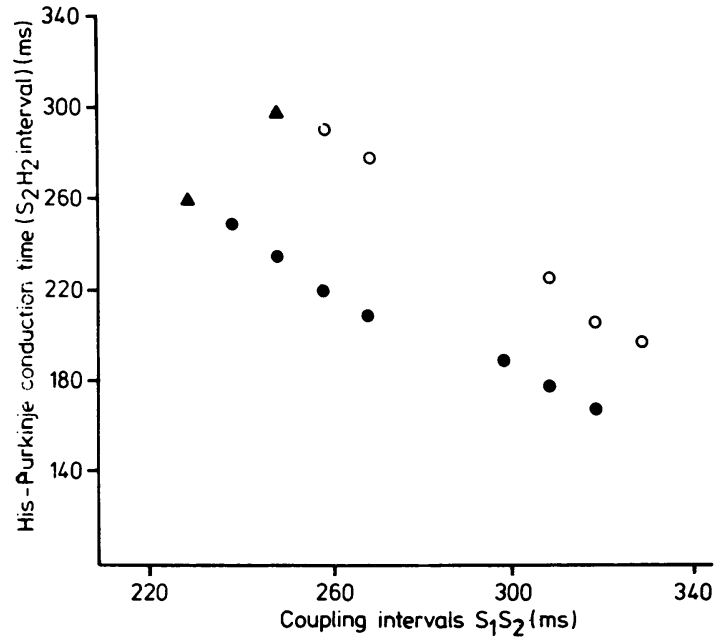

Fig. 2 Case 8: effect of amiodarone on retrograde His-Purkinje conduction times of the premature ventricular complexes. In the control study $\mathrm{H}_{2}$ emerged from the ventricular electrogram $\left(V_{2}\right)$ at an $\mathrm{S}_{1} \mathrm{~S}_{2}$ interval of $320 \mathrm{~ms}$. At shorter $\mathrm{S}_{1} \mathrm{~S}_{2}$ intervals the $\mathrm{S}_{2} \mathrm{H}_{2}$ intervals progressively increased and a zone of $\mathrm{S}_{2} \mathrm{H}_{2}$ block (gap) occurred between $S_{1} S_{2}$ intervals of 290 and $280 \mathrm{~ms}$. After amiodarone, $\mathrm{H}_{2}$ emerged from $V_{2}$ at an $\mathrm{S}_{1} \mathrm{~S}_{2}$ interval of $330 \mathrm{~ms}$ and the zone of $S_{2} H_{2}$ block became wider and occurred between $\mathrm{S}_{1} \mathrm{~S}_{2}$ intervals of 300 and $280 \mathrm{~ms}$. Effective refractory period of ventricular muscle was reached at an $S_{1} S_{2}$ interval of $230 \mathrm{~ms}$ in the control study and of $250 \mathrm{~ms}$ after amiodarone. 0 , control values; $\bigcirc$, values after amiodarone; $\Delta$, effective refractory period of ventricular muscle.

linear increase in $\mathrm{S}_{2} \mathrm{H}_{2}$ interval until the effective refractory period of the ventricular muscle or that of the His-Purkinje system was reached (Figs. 1 and 2). At longer $S_{1} S_{2}$ intervals latency could not be identified, but at shorter coupling intervals encroaching on the effective refractory period of ventricular muscle latency ranging from 5-25 ms in the control studies and 10-35 ms after amiodarone was observed in all patients. Thus at shorter $\mathrm{S}_{1} \mathrm{~S}_{2}$ intervals, $\mathrm{V}_{2} \mathrm{H}_{2}$ intervals were shorter than the $\mathrm{S}_{2} \mathrm{H}_{2}$ intervals. After amiodarone, the $\mathrm{H}_{2}$ deflection emerged from the ventricular electrogram of the extrasystole at a longer $\mathrm{S}_{1} \mathrm{~S}_{2}$ interval than the control value, and, at comparable $S_{1} S_{2}$ intervals, the $\mathrm{S}_{2} \mathrm{H}_{2}$ intervals were longer than the control values (Figs. 1 and 2). Compared with the control values, the longest $\mathrm{S}_{2} \mathrm{H}_{2}$ intervals after amiodarone were longer in 10 patients and the same in one.

\section{HV INTERVAL}

After amiodarone the $\mathrm{HV}$ interval was prolonged in seven patients and unchanged in four (Fig. 3). The mean HV interval was significantly longer after amiodarone (Table).

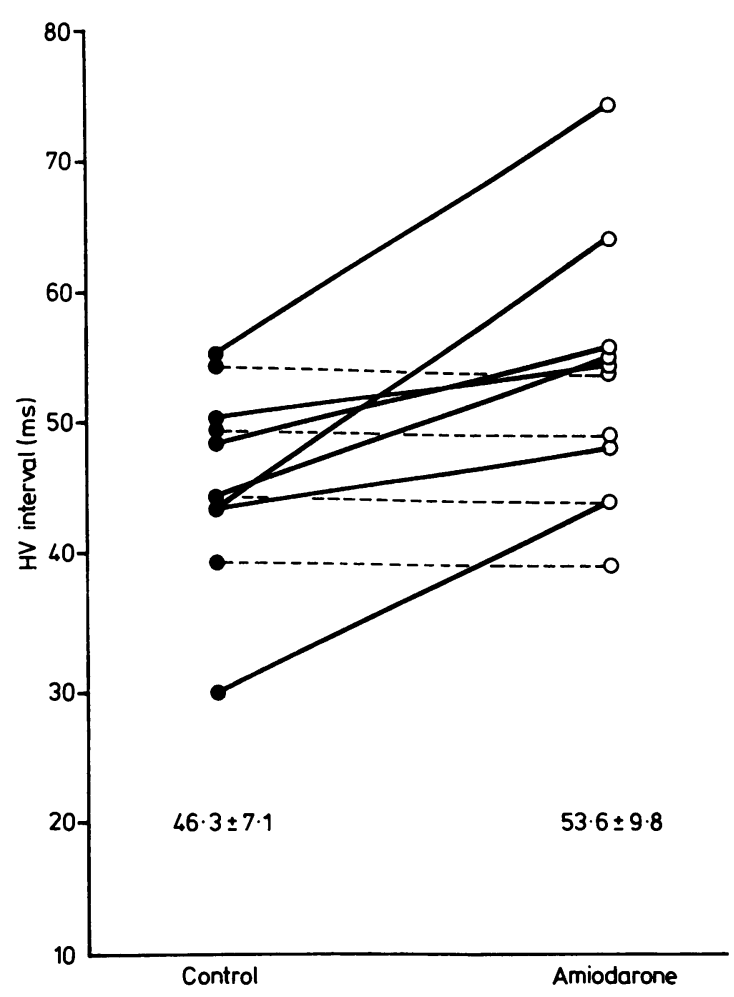

Fig. 3 Effect of amiodarone on the HV interval in all 11 patients in control study and after amiodarone. After amiodarone the $H V$ interval increased in seven patients (unbroken lines) and remained unchanged in four (broken lines).

$\mathrm{S}_{2} \mathrm{H}_{2}$ BLOCK (GAP) ZONES

$\mathrm{S}_{2} \mathrm{H}_{2}$ block is a form of retrograde gap within the His-Purkinje system in which the extrasystole $S_{2}$ is blocked between the site of stimulation and that where the His bundle recording is made. ${ }^{17} \mathrm{~S}_{2} \mathrm{H}_{2}$ block zones ranging from $10-40 \mathrm{~ms}$ were observed in six patients during the control study. After amiodarone, $\mathrm{S}_{2} \mathrm{H}_{2}$ block zones were not abolished in any patient, became wider or increased in number in three patients (Fig. 2), and appeared in four additional patients.

\section{RE-ENTRY WITHIN THE HIS-PURKINJE SYSTEM}

In the control study re-entry within the His-Purkinje system $\left(V_{3} \text { phenomenon }\right)^{17}$ was observed in five patients, and the zone of re-entry varied from 10 to 50 ms (Fig. 1). After amiodarone, the $V_{3}$ phenomenon was abolished in three patients and occurred over a narrower zone in two. In both of these patients reentry was initiated at a longer coupling interval and required considerably longer conduction $\left(\mathrm{S}_{2} \mathrm{H}_{2}\right)$ delay (Fig. 1). After amiodarone re-entry occurred in two 


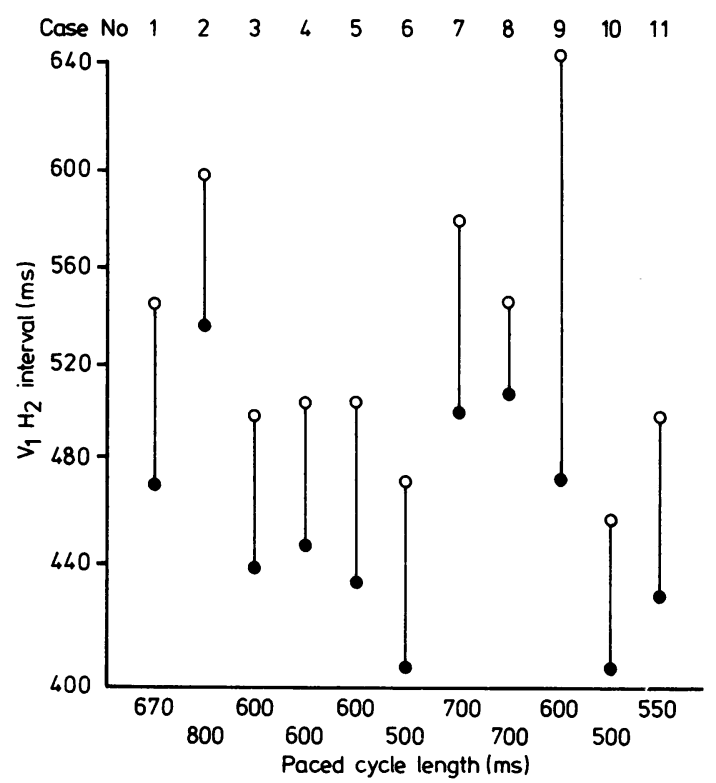

Fig. 4 Effect of amiodarone on the functional refractory period of the His-Purkinje system ( $V_{1} H_{2}$ interval). O, control values; $\mathrm{O}$, values after amiodarone.

additional patients who did not show re-entry in the control study.

\section{REFRACTORY PERIODS OF THE HIS-PURKINJE SYSTEM}

Amiodarone significantly prolonged the relative, effective, and functional refractory periods of the His-Purkinje system (Table). Fig. 4 shows the effect on functional refractory period of the His-Purkinje system before and after amiodarone for all patients. Both the effective and the functional refractory periods of ventricular muscle increased significantly after amiodarone in all patients (Table).

\section{VENTRICULAR TACHYCARDIA}

Sustained ventricular tachycardia could be induced in 10 patients in the control study and in four after amiodarone. The rate of induced ventricular tachycardia was slower in all four patients after amiodarone. During a mean follow up period of 14.6 months tachycardia did not recur in nine of 10 patients with ventricular tachycardia. In one patient without inducible tachycardia amiodarone was withdrawn because the drug failed to control spontaneous tachycardia.

\section{Discussion}

Our results show that amiodarone prolongs the con- duction time of the extrasystoles regardless of its effect on the HV interval of sinus complexes. In our study, amiodarone prolonged the $\mathrm{S}_{2} \mathrm{H}_{2}$ interval at comparable $\mathrm{S}_{1} \mathrm{~S}_{2}$ intervals in all patients and the longest $\mathrm{S}_{2} \mathrm{H}_{2}$ interval in 10 of 11 patients. Similarly, the functional refractory period of the His-Purkinje system was prolonged in all patients.

The $\mathrm{S}_{2} \mathrm{H}_{2}$ interval represents the total conduction delay encountered by the ventricular extrasystole during its propagation from the site of stimulation to the site of His bundle recording. Data from experimental studies show that conduction delay and block can occur within the ventricular muscle, muscle-Purkinje junction, and the Purkinje bundle branch system. 1820 Since the conduction delays at each of these sites cannot be measured with the techniques used in our study what portion of the $\mathrm{S}_{2} \mathrm{H}_{2}$ interval reflects the conduction time in the His-Purkinje system cannot be defined. Although the duration of latency increased in all patients after amiodarone, prolongation of the $\mathrm{HV}$ and the longest $\mathrm{S}_{2} \mathrm{H}_{2}$ intervals and the widening of $\mathrm{S}_{2} \mathrm{H}_{2}$ block zones in many of these patients suggest that the slowing of conduction in the His-Purkinje system contributed to $\mathrm{S}_{2} \mathrm{H}_{2}$ prolongation. Our observation that amiodarone prolongs the $\mathrm{S}_{2} \mathrm{H}_{2}$ interval both in patients with and without $\mathrm{HV}$ interval prolongation is consistent with the results of in vitro studies. ${ }^{21} 22$

The reasons for the absence of HV interval prolongation in some clinical studies and its presence in only some patients in most other studies including ours are not known, but possible explanations include variability of patient selection, doses used, and duration of treatment. Another possible explanation for the variable effects of amiodarone on the HV interval may be the presence or absence of disease in the HisPurkinje system.1121 Rosenbaum et al reported exacerbation of pre-existing right bundle branch block during long term treatment with amiodarone. ${ }^{21}$ In our study, nine of 11 patients had organic heart disease.

Very few data are available regarding the effect of long term treatment with amiodarone ${ }^{11}$ on refractoriness of the His-Purkinje system, and there are conflicting data on the effect of intravenous amiodarone. ${ }^{512}$ Touboul et al studied the effect of 5 $\mathrm{mg} / \mathrm{kg}$ of intravenous amiodarone and reported that the drug prolonged the relative refractory period of the His-Purkinje system in five of seven patients. ${ }^{5}$ In contrast, Cabasson et al, using larger doses of amiodarone, found no change in the refractory periods of the His-Purkinje system. ${ }^{12}$ In the present study, the functional and relative refractory periods of the His-Purkinje system were prolonged in all patients, and the $\mathrm{S}_{2} \mathrm{H}_{2}$ block zones became wider and occurred in more patients. On average, the functional 
refractory period of the His-Purkinje system increased by $72 \mathrm{~ms}$, which was $14 \%$ higher than the control value. The prolongation of conduction and refractoriness of the His-Purkinje system observed in this study cannot be attributed to time dependent changes because spontaneous variability would be expected to produce both increases and decreases in control data.

Our observations are in agreement with previously reported findings ${ }^{8} 911$ that there is a dissociation between the ability to induce tachycardia in the laboratory and the clinical response to amiodarone. In the present study of a small number of patients the clinical outcome of treatment could not be correlated with the observed changes in the electrophysiological properties of the His-Purkinje system and the ventricular myocardium. A better understanding of the mechanism of the antiarrhythmic action of amiodarone must await further study.

This study was supported in part by a grant from the American Heart Association, Kentucky Affiliate, USA, and was presented at the 32nd Annual Scientific Sessions of the American College of Cardiology, New Orleans, LA, March 1983.

\section{References}

1 Vastesaeger M, Gillot P, Rasson G. Etude clinique d'une nouvelle medication anti-angoreuse. Acta Cardiol (Brux) 1967; 22: 483-500.

2 Rosenbaum MB, Chiale PA, Ryba D, Elizari MV. Control of tachyarrhythmias associated with WolffParkinson-White syndrome by amiodarone hydrochloride. Am $\mathcal{F}$ Cardiol 1974; 34: 215-23.

3 Kaski JC, Girotti LA, Messuti H, Rutitzky B, Rosenbaum MB. Long-term management of sustained, recurrent, symptomatic ventricular tachycardia with amiodarone. Circulation 1981; 64: 273-9.

4 Ward DE, Camm AJ, Spurrell RAJ. Clinical antiarrhythmic effects of amiodarone in patients with resistant paroxysmal tachycardias. Br Heart $\mathcal{F}$ 1980; 44: 91-5.

5 Touboul P, Huerta F, Porte J, Delahaye J-P. Bases électrophysiologiques de l'action antiarrhythmique de l'amiodarone chez l'homme. Arch Mal Coeur 1976; 69: 845-53.

6 Rowland E, Krikler DM. Electrophysiological assessment of amiodarone in treatment of resistant supraventricular arrhythmias. Br Heart $\mathcal{F}$ 1980; 44: 82-90.

7 Wellens HJJ, Lie KI, Bär FW, et al. Effect of amiodarone in the Wolff-Parkinson-White syndrome. Am 7 Cardiol 1976; 38: 189-94.

8 Waxman HL, Groh WC, Marchlinski FE, et al. Amiodarone for control of sustained ventricular tachyarrhythmia: clinical and electrophysiologic effects in 51 patients. Am $\mathcal{F}$ Cardiol 1982; 50: 1066-74.

9 Heger JJ, Prystowsky EN, Jackman WM, et al. Amiodarone: clinical efficacy and electrophysiology during long-term therapy for recurrent ventricular tachycardia or ventricular fibrillation. $N$ Engl f Med 1981; 305: 539-45.

10 Nademanee K, Hendrickson JA, Cannom DS, Goldreyer $\mathrm{BN}$, Singh BN. Control of refractory life-threatening ventricular tachyarrhythmias by amiodarone. Am Heart $\mathcal{F}$ 1981; 101: 759-68.

11 Finerman WB Jr, Hamer A, Peter T, Weiss D, Mandel WJ. Electrophysiologic effects of chronic amiodarone therapy in patients with ventricular arrhythmias. $\mathrm{Am}$ Heart f 1982; 104: 987-96.

12 Cabasson J, Puech P, Mellet JM, Guimond C, Bachy C, Sassine A. Analyse des effets électrophysiologiques de l'amiodarone par l'enregistrement simultané des potentiels d'action monophasiques et du faisceau de His. Arch Mal Coeur 1976; 69: 691-9.

13 Scherlag BJ, Lau SH, Helfant RH, Berkowitz WD, Stein E, Damato AN. Catheter technique for recording His bundle activity in man. Circulation 1969; 39: 13-8.

14 Damato AN, Lau SH, Bobb GA. Studies on ventriculoatrial conduction and the reentry phenomenon. Circulation 1970; 41: 423-35.

15 Wit AL, Weiss MB, Berkowitz WD, Rosen KM, Steiner C, Damato AN. Patterns of atrioventricular conduction in the human heart. Circ Res 1970; 27: 345-59.

16 Dhatt MS, Gomes JAC, Reddy CP, et al. Effects of phenytoin on refractoriness and conduction in the human heart. 7 Cardiovasc Pharmacol 1979; 1: 3-18.

17 Reddy CP, Damato AN, Akhtar M. Intra His Purkinje gap phenomenon during retrograde conduction in man. f Electrocardiol 1981; 14: 1-7.

18 Moore EN. Microelectrode studies on retrograde concealment of multiple premature ventricular responses. Circ Res 1967; 20: 88-98.

19 Mendez C, Mueller WJ, Merideth J, Moe GK. Interaction of transmembrane potentials in canine Purkinje fibers and at Purkinje fiber-muscle junctions. Circ Res 1969; 24: 361-72.

20 Myerburg RJ, Gelband H, Hoffman BF. Functional characteristics of the gating mechanism in the canine A-V conducting system. Circ Res 1971; 28: 136-47.

21 Rosenbaum MB, Chiale PA, Halpern MS, et al. Clinical efficacy of amiodarone as an antiarrhythmic agent. $A m \mathfrak{F}$ Cardiol 1976; 38: 934-44.

22 Mason JW, Hondeghem LM, Katzung BG. Amiodarone blocks inactivated cardiac sodium channels. Pflügers Arch 1983; 396: 79-81. 